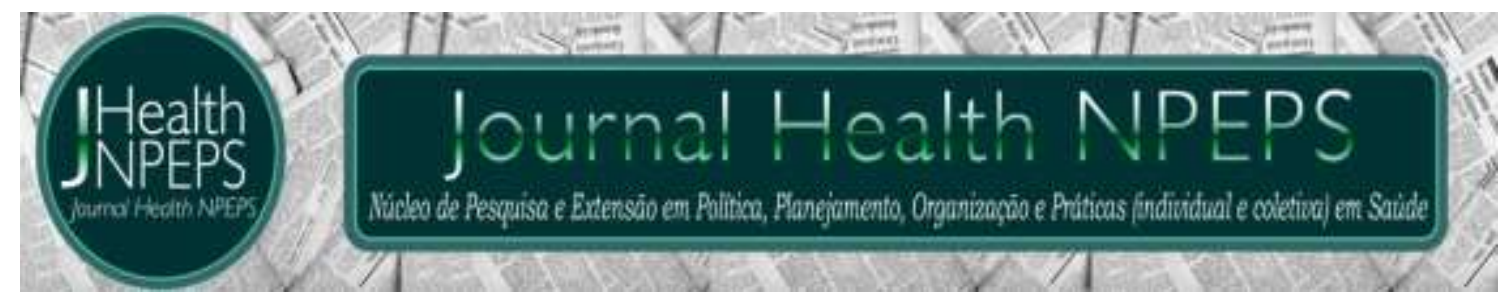

http://dx.doi.org/10.30681/252610102999

EDITORIAL

\title{
Humanos vs micro-organismos: quem vencerá esta guerra?
}

\section{Eryvaldo Sócrates Tabosa do Egito ${ }^{1}$}

O medicamento ideal é objeto de desejo desde o início da compreensão do homem sobre a existência de microrganismos patogênicos e as consequências da presença destes na homeostase. Em 1908, o conceito de medicamento "ideal" foi proposto pelo imunologista Paul Erlich, que o denominou de "Bala Mágica"1. Tal conceito se baseia em um aparato ou molécula capaz de atuar somente no local da doença (sítio de ação), restaurando o equilíbrio homeostático, sem prejudicar outros tecidos do paciente. Após a teorização do conceito, várias tecnologias, advindas das tentativas de alcançar esta meta, foram e continuam sendo desenvolvidas.

Apesar do conceito da "Bala Mágica" ser fruto do início do século XX, portanto anterior a descoberta do primeiro antibiótico - a penicilina, descoberta em 1928 - tal terminologia jamais foi aplicada a medicamentos (formulações farmacêuticas) em geral. Na verdade, o que mais se discute hoje é o quanto os medicamentos, contendo novas moléculas, continuam apresentando efeitos adversos.

Por outro lado, considerando os quase 90 anos de utilização de antibióticos, sempre foi esperado que os micro-organismos desenvolvessem mecanismos de resistência naturais e a busca por novas moléculas com propriedades farmacológicas semelhantes as antigas, mas com mecanismo de ação distintos, foi e persistem sendo o foco das pesquisas na indústria farmacêutica em geral. Contudo, as resistências aos antimicrobianos, para ficar nesta classe de moléculas, têm sido observadas não somente para

\footnotetext{
${ }^{1}$ Farmacêutico. Pós Doutor. Professor Titular de Tecnologia Farmacêutica da Universidade Federal do Rio Grande do Norte (UFRN) e Coordenador do Programa de Pós Graduação em Nanotecnologia Farmacêutica (UFRN). Natal Rio Grande do Norte - Brasil. E-mail: socratesegito@gmail.com ORCID ID: https://orcid.org/0000-0002-2180-3991
} 
fármacos antigos, mas também para aqueles desenvolvidos nos últimos 30 anos, como o tazobactam². Órgãos executivos, como a Organização Mundial da Saúde e o Ministério da Saúde Brasileiro, demonstram uma preocupação cada vez maior acerca do incremento de surgimento de "superbactérias" não somente no interior dos hospitais, mas difundidos no meio ambiente em geral. Por conseguinte, um importante trabalho vem sendo desenvolvido nos últimos anos por equipes multiprofissionais em hospitais e centros de saúde visando padronizar a utilização de fármacos a fim de diminuir a velocidade de aparecimento de cepas resistentes. Efetivamente, estudos fármacoeconômicos e farmacoepidmiológicos são essenciais para contemplação e concretização dos objetivos descritos acima.

No tocante ao problema alentado anteriormente, para minimizar o entrave da resistência antimicrobiana, faz-se necessário o desenvolvimento de novas moléculas terapêuticas através da química farmacêutica. Ademais, ressalta-se que dentre as mais variadas áreas da farmácia, a química farmacêutica proveu diversas novas classes de antimicrobianos (B-lactâmicos, quinolonas, glicopeotídeos, macrolídeos, polimixinas, dentre outros). No entanto, a síntese de novos fármacos sozinha não foi capaz de gerar "Balas Mágicas" e, por conseguinte, a especificidade de ação apregoada por tal teoria jamais foi alcançada. Acreditamos que para atingir tal objetivo, é necessário o investimento maciço não somente da química farmacêutica, mas também de todas as áreas das ciências farmacêuticas relacionadas ao medicamento. Estas áreas, por sua vez, nos últimos anos, têm se dedicado muito mais ao tratamento do câncer e doenças crônicas, em detrimento das doenças infecciosas. Por tal razão, outras fontes de produção de insumos terapêuticos como a biotecnologia, para novas moléculas, e a nanotecnologia, para novas formulações, estão em pleno desenvolvimento para a produção das ditas formas farmacêuticas inteligentes desde as últimas décadas.

Os novos sistemas terapêuticos tem alcançado resultados promissores através dos novos materiais, produzindo, por conseguinte, carreadores de fármacos mais eficientes. No tocante a esta estratégia, muito tem sido estudado o desenvolvimento de sistemas de liberação de fármacos empregando a nanotecnologia farmacêutica, em que a molécula seria liberada 
somente no local de ação. Como consequência, os mecanismos de resistência poderiam ser potencialmente diminuídos, haja vista que o micro-organismo só "enxergaria" o fármaco quando o mesmo estivesse exercendo sua ação farmacológica. Princípio este semelhante ao Cavalo de Troia.

Assim, a nanotecnologia farmacêutica também se destaca por tornar viável o uso de moléculas ativas que não apresentam as propriedades fisicoquímicas e terapêuticas ideais (Regra dos múltiplos de 5 de Lipinski) ${ }^{3}$ para sua incorporação em formulações ditas convencionais. Efetivamente, esta estratégia pode ser aplicada para "renovar" o poder do arsenal terapêutico antigo encontrando uma nova forma de liberação do medicamento no organismo, modificando portanto sua biodisponibilidade. Dessa forma, moléculas para as quais os micro-organismos hoje apresentam resistência podem voltar a ser ativas se forem empregadas outras formas de ataque ao patógeno. Moléculas antes ditas impossíveis de serem absorvidas por via oral, hoje, podem através da nanotecnologia, ter sua permeação completamente modificada. Parasitas intracelulares, o causador da leishmaniose sendo o maior exemplo, também podem ser alcançados obedecendo plenamente ao conceito da "Bala Mágica" através de carreadores nanoestruturados que "navegam" no organismo de forma intacta só liberando o fármaco quando no interior da célula hospedeira.

Apesar dos carreadores nanotecnológicos já não ser mais necessariamente uma novidade na indústria farmacêutica visto que sistemas lipossomais para anfotericina B e doxorrubicina estão no mercado desde meados da década de 1990, pouco se avançou quanto ao lançamento de novos produtos. Sistemas carreadores nanoparticulados têm sido bastante empregados em ensaios clínicos, porém o foco principal, como relatado anteriormente, tem sido o tratamento de cânceres, provavelmente devido a gravidade desta patologia e por aportar um grande retorno econômico para as indústrias farmacêuticas em geral. Entretanto, um tremendo esforço deve ser empenhado pelos cientistas os quais lidam com nanotecnologia para ampliar o arsenal terapêutico, sobretudo no tocante as doenças negligenciadas, como, por exemplo, a tuberculose e inúmeras outras parasitoses, que ainda 
acomentem nossa população e são de baixo interesse comercial. Logo, este é um desafio futuro a ser perseguido pelas políticas públicas de nosso país.

Faltando pouco mais de 10 anos para completar um século do seu descobrimento, o uso da penicilina ainda está longe de ser um tratamento $100 \%$ eficaz contra as infecções. Por conseguinte, o sonho do medicamento ideal está ainda mais distante e poucas evidências demonstram que teremos um único sistema carreador perfeito ${ }^{4}$. Por fim, esforços não podem ser medidos para que nas próximas décadas obtenhamos o total controle sobre as infecções, seja através da prevenção, bem como por meio de um tratamento eficiente. Neste ponto, acreditamos que estudos voltados para a nanotecnologia farmacêutica podem aportar a solução. Cabe a nós iniciarmos esta batalha com o intuito de garantirmos que os humanos consigam pelo menos viver pacificamente com os micro-organismos.

\section{REFERÊNCIAS}

1. Strebhardt K, Ullrich A. Paul Ehrlich's magic bullet concept: 100 years of progress. Nature Reviews Cancer. 2008; 8:473-80.

2. Lee J, Oh CE, Choi EH, Lee HJ. The impact of the increased use of piperacillin/tazobactam on the selection of antibiotic resistance among invasive Escherichia coli and Klebsiella pneumoniae isolates. Int J Infect Dis. 2013; 17:e638-643.

3. Lipinski CA, Lombardo F, Dominy BW, Feeney PJ. Experimental and computational approaches to estimate solubility and permeability in drug discovery and development settings. Adv Drug Deliv Rev. 2001; 46:3-26.

4. Toporkiewicz M, Meissner J, Matusewicz L, Czogalla A, Sikorski AF. Toward a magic or imaginary bullet? Ligands for drug targeting to cancer cells: Principles, hopes, and challenges. Int J Nanomedicine. 2015; 10:1399-414. 